\title{
Compression Properties of Woven Carpet Performance under Dynamic Loading
}

\author{
Deniz Vuruşkan', Esin Sarıoğlu², Halil İbrahim Çelik², Hatice Kübra Kaynak ${ }^{2}$ \\ ${ }^{1}$ Gaziantep University, Faculty of Fine Arts, Department of Fashion and Textile Design \\ ${ }^{2}$ Gaziantep University, Faculty of Engineering, Textile Engineering Department
}

\begin{tabular}{l} 
Article Info \\
\hline Article history: \\
Received May $27^{\text {th }}, 2017$ \\
Revised June $15^{\text {th }}, 2017$ \\
Accepted June $17^{\text {th }}, 2017$ \\
\hline
\end{tabular}

\section{Keyword:}

Acrylic

Dynamic loading

Wilton woven carpet

Pile height

Pile denisty

\begin{abstract}
Although carpets are seen as decorative products for consumers, it is important that they must have optimum quality performance. The most important features affecting quality performance are pile fiber, pile yarn, pile height, pile density, carpet surface structure (cut pile or loop pile), carpet construction etc. During usage the carpet are exposed to a number of forces due to compressional loading such as dynamic or static. To counteract these forces, the resilience of pile yarn is vital. This paper demonstrates the influence of pile density and pile height of structure parameters on compression performance which was exposed to dynamic loading. In that respect, acrylic fiber was used as pile to manufacture Wilton face-to-face cutpile carpets at two pile densities (2400 piles $/ \mathrm{dm}^{2}, 2880$ piles $\left./ \mathrm{dm}^{2}\right)$ and three pile heights $(7 \mathrm{~mm}, 11 \mathrm{~mm}$ and $16 \mathrm{~mm})$. To determine the compression properties, carpets were subjected to dynamic loading at 50, 100, 200 and 1000 impacts. Thickness of carpets was taken at each of these four impacts. Finally, thickness loss of carpets as well as compression performance was detected. In order to identify the effect of pile density, pile height and number of impact on thickness loss of carpet after dynamic loading, analysis of variance was performed statistically. Results showed that pile height, pile density and number of impact have statistically significance on compression performance of carpet samples.
\end{abstract}

\section{Corresponding Author:}

\section{Esin SARIOĞLU}

Gaziantep University, Faculty of Engineering,

Textile Engineering Department, 27310

Şehitkamil/ Gaziantep, Turkey.

Email: sarioglu@gantep.edu.tr

\section{Introduction}

Carpet is predominantly used in home floor covering as an indispensable decorative product and also preferred by its heat and sound insulation feature. Compression performance in general terms of mechanical properties influences carpet performance under dynamic or static loads. Carpet thickness will be deformed when it is exposed to dynamic and static loads which are created by walking and furniture, respectively. During daily usage of the carpet, thickness loss is directly affected by raw material, pile height, carpet construction, pile density etc. There are a lot of studies focused on effects of these parameters on carpet performance based on static loading, dynamic loading and compressibility [1-15]. Javidpanah et al. studied cut-pile carpets made of heat process modified polyester pile yarn thickness loss of cut-pile carpets after dynamic loading. Four different 1800 denier and 96 filament in the cross section of air textured polyester pile yarns; normal, frieze, heat set and twist heat set were used as pile yarn. In order to analyze the carpet compression performance 50, 100, 200, 500, 1000 and 2000 dynamic impacts were acted on carpet samples. It was stated that physical and mechanical properties of air textured polyester pile yarns do not have significant changes after heat processing [4]. Çelik and Koç investigated on some selected carpet samples made of wool, 
acrylic and polypropylene pile yarns to evaluate the performance of carpets under dynamic loading. In this study, carpets were exposed 50,100, 200, 500 and 1000 dynamic impacts and then thickness losses were analyzed. They put forward that an increase in the number of impacts increase the thickness loss. It was found that acrylic fiber carpet had highest recovery capability than wool and polypropylene fiber carpets [13]. Çelik determined the effect of acrylic fineness, 2.75 denier, 6 denier and 8 denier, on carpet performance. Among the all analyses in order to identify carpet performance, dynamic loading tests were performed under 50, 100, 200, 1000 and 2000 impacts. It was resulted that acrylic fiber fineness had significant effect on thickness loss of carpet samples. The highest thickness loss was detected at carpet sample produced from acrylic pile yarn with 2.75 denier fiber fineness [8].

The aim of this study is to investigate the influences of pile height and pile density on woven carpet compression performance under dynamic loading with 50, 100, 200 and 1000 impacts. To determine the relationships between independent variable (pile height, pile density and number of impact) and response variable (thickness loss) multivariate variance analysis (MANOVA) was performed by SPSS package program.

\section{Materials and Methods}

Six acrylic cut-pile carpets were manufactured by Wilton face-to-face carpet weaving machine with three rapiers which enables three weft shots. The structure for all carpets was chosen as $2 / 3 \mathrm{~V}$ weave construction which is illustrated in Figure 1.

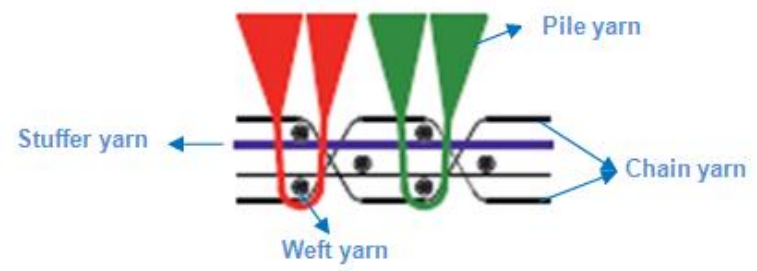

Figure 1. 2/3 V weave construction [16,17]

Acrylic fiber was used as pile with 5.6 denier linear density. All carpet production parameters were kept constant such as machine speed, weft and warp yarns used, construction. Carpet compositions are shown in Table 1. Carpet specifications are given in Table 2 with respect to pile height and pile density variables.

Table 1. Carpet samples composition

\begin{tabular}{ccccc}
\hline & \multirow{2}{*}{ Pile yarn } & \multicolumn{2}{c}{ Warp yarn } & Weft \\
\cline { 3 - 5 } & Acylic & Stuffer yarn & Chain yarn & \\
\hline Material & $20 \%$ Cotyester/ & Polyester & \multirow{2}{*}{ Jute } \\
$\begin{array}{c}\text { Yarn linear } \\
\text { density, tex }\end{array}$ & 200 & 197 & 89 & 491 \\
\hline
\end{tabular}

Table 2. Carpet specifications

\begin{tabular}{cccccc}
\hline $\begin{array}{c}\text { Warp } \\
\text { density } \\
(\mathbf{e n d s / d m})\end{array}$ & $\begin{array}{c}\text { Weft } \\
\text { density } \\
(\text { picks/dm) }\end{array}$ & $\begin{array}{c}\text { Pile } \\
\text { Density } \\
\left(\text { piles/dm }^{2}\right)\end{array}$ & $\begin{array}{c}\text { Pile } \\
\text { Height } \\
(\mathbf{m m})\end{array}$ & $\begin{array}{c}\text { Pile } \\
\text { Weight } \\
\left(\mathbf{g} / \mathbf{m}^{2}\right)\end{array}$ & $\begin{array}{c}\text { Carpet } \\
\text { Weight } \\
\left(\mathbf{g} / \mathbf{m}^{2}\right)\end{array}$ \\
\hline 48 & 50 & 2400 & 7 & 918.549 & 1929.882 \\
48 & 60 & 2880 & 7 & 1205.600 & 2413.000 \\
48 & 50 & 2400 & 11 & 1374.654 & 2476.000 \\
48 & 60 & 2880 & 11 & 1611.245 & 2846.064 \\
48 & 50 & 2400 & 16 & 1980.400 & 3071.200 \\
48 & 60 & 2880 & 16 & 2431.240 & 3728.400 \\
\hline
\end{tabular}


All carpet specimens were conditioned with $65 \pm 4 \%$ relative humidity and $20 \pm 2{ }^{\circ} \mathrm{C}$ temperature according to ISO 139:2005 [18]. Five test specimens were prepared as $125 \mathrm{~mm} * 125 \mathrm{~mm}$ dimensions for each carpet. In order to perform dynamic loading test WIRA dynamic loading machine which drops free falling weight on carpet specimen at every five seconds was used. Carpet specimen was clamped on to a steel plate that is slowly and continuously traversed in such a way that there is $3.2 \mathrm{~mm}$ movement between each drop of the weight at each impact. Tests were conducted according BS ISO 2094:1999 [8,19,20]. Before applying dynamic loading all carpet thickness were measured in accordance with ISO 1765:1986 with WIRA digital thickness gauge under standard pressure of $2 \pm 0.2 \mathrm{kPa}$ and this process repeated after 50, 100, 200 and 1000 impacts immediately [21]. Thickness loss in percentage was determined as a difference between the thickness at zero impact and at each stage of impact by using Equation (1).

$$
\text { Thickness loss, } \%=\frac{h_{0}-h_{c}}{h_{o}} \times 100
$$

where: $h_{0}$ is initial thickness and $h_{c}$ is thickness after dynamic loading at each stage of impacts.

For statistical analysis SPSS package program was used to assess the effect size and significance of pile height, pile density and number of impact on thickness loss of carpet for each stage of impact at $95 \%$ confidence interval.

\section{Results and Discussion}

Thickness losses in percentage of acyclic carpets with different pile densities and pile heights after 50, 100, 200 and 1000 impacts are shown in Figure 2.

Thickness loss of acrylic cut-pile carpets increases from 50 to 1000 impacts with the increase in number of impact. Performance of carpets at $7 \mathrm{~mm}$ pile height for each pile density against compression is higher than that of $11 \mathrm{~mm}$ and $16 \mathrm{~mm}$ carpets. In addition, it is clearly seen that increase in pile density contributes to the compression performance of carpets with $11 \mathrm{~mm}$ and $16 \mathrm{~mm}$ pile heights. This situation can be explained with having more pile yarns within the unit area results higher resistance against dynamic load impacts. On the other hand, the same situation is not directly observed for carpets with $7 \mathrm{~mm}$ pile height. Thickness loss difference between 2400 piles $/ \mathrm{dm}^{2}$ is lower $3 \%$ than that of 2880 piles $/ \mathrm{dm}^{2}$ for 100 impacts.

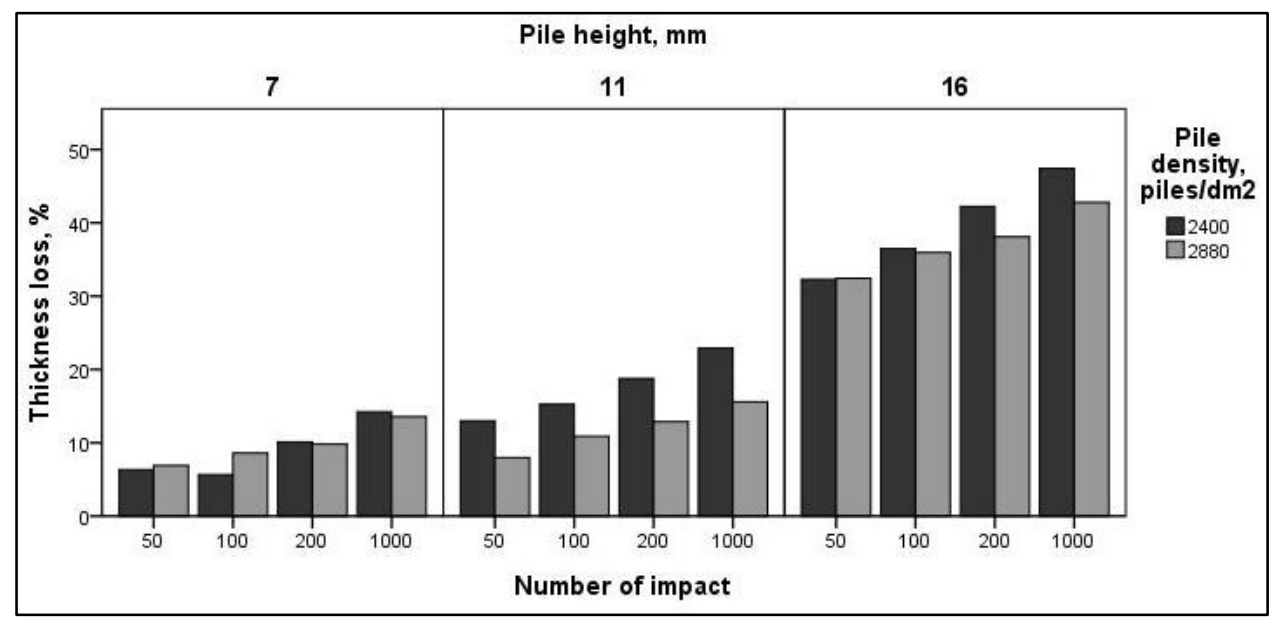

Figure 2. Thickness loss of cut-pile carpet samples versus to number of impact

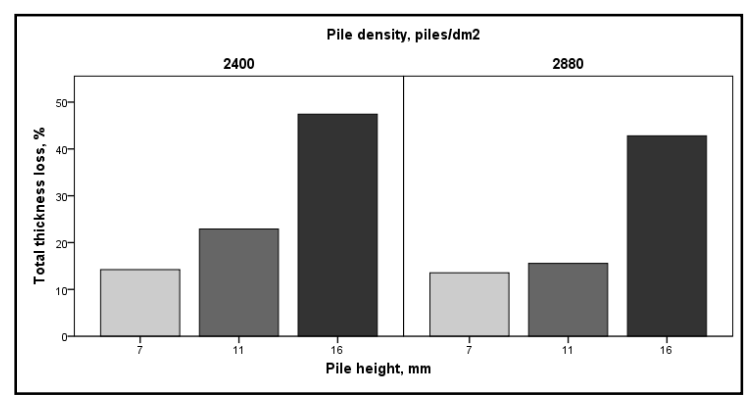

Figure 3. Total thickness loss of cut-pile acrylic carpet samples 
Total thickness loss in percent of cut-pile acrylic carpet samples with different pile density and pile height is shown in Figure 3. When constant pile height is taken into consideration, the difference of thickness loss in percent for 2400 piles $/ \mathrm{dm}^{2}$ carpet has the higher value of $4.7 \%$ than 2880 piles $/ \mathrm{dm}^{2}$. This result is similar for $11 \mathrm{~mm}$ and $16 \mathrm{~mm}$ cut-pile carpets with the thickness loss value of $32 \%$ and $9.7 \%$, respectively. In conclusion, the influence of pile density on thickness loss is clearly stated that the higher the pile density, the lower the thickness loss after dynamic loading at 1000 impacts.

MANOVA results for thickness loss after dynamic loading for independent variables are seen in Table 3 . When the effect of pile height, pile density and number of impact on thickness loss is examined, thickness loss values are seen as statistically significant $\left(\mathrm{R}^{2}=96.6 \%\right)$.

In order to evaluate the effects of subgroups for number of impact and pile height (pile density was not considered because of lower than three subgroups), Duncan's multivariate range tests were achieved and results are illustrated in Table 4 and Table 5, respectively. In Table 4, increase in number of impacts affects the carpet thickness loss negatively. Furthermore, carpets with higher pile height have lower resistance to dynamic loading with higher thickness loss (Table 5).

Table 3. MANOVA for thickness loss under dynamic loading

\begin{tabular}{|c|c|c|c|c|c|}
\hline Source & $\begin{array}{l}\text { Sum of } \\
\text { Squares }\end{array}$ & df & $\begin{array}{l}\text { Mean } \\
\text { Square }\end{array}$ & $\mathbf{F}$ & Sig. \\
\hline Corrected Model & $17024.242^{\mathrm{a}}$ & 23 & 740.184 & 88.220 & .000 \\
\hline Intercept & 41680.710 & 1 & 41680.710 & 4967.758 & .000 \\
\hline Number of impact & 1242.777 & 3 & 414.259 & 49.374 & .000 \\
\hline Pile height, $\mathrm{mm}$ & 15343.407 & 2 & 7671.704 & 914.360 & .000 \\
\hline Pile density, piles $/ \mathrm{dm}^{2}$ & 142.241 & 1 & 142.241 & 16.953 & .000 \\
\hline Number of impact $*$ Pile height & 75.874 & 6 & 12.646 & 1.507 & .188 \\
\hline Number of impact $*$ Pile density & 50.026 & 3 & 16.675 & 1.987 & .123 \\
\hline Pile height* Pile density & 158.538 & 2 & 79.269 & 9.448 & .000 \\
\hline $\begin{array}{l}\text { Number of impact } * \text { Pile height } * \\
\text { Pile density }\end{array}$ & 11.381 & 6 & 1.897 & .226 & .967 \\
\hline Error & 604.098 & 72 & 8.390 & & \\
\hline Total & 59309.050 & 96 & & & \\
\hline Corrected Total & 17628.340 & 95 & & & \\
\hline
\end{tabular}

a. R Squared $=.966$ (Adjusted R Squared $=.955$ )

Table 4. Duncan's multivariate range test results according to number of impacts

\begin{tabular}{lccccc}
\hline \multicolumn{5}{c}{ Duncan $^{\mathrm{a}, \mathrm{b}}$} \\
\cline { 3 - 6 } Number of impact & $\mathrm{N}$ & 1 & 2 & 3 & 4 \\
\hline 50 & 24 & 16.4952 & & & \\
100 & 24 & & 18.7959 & & \\
200 & 24 & & 21.9790 & \\
1000 & 24 & & & 26.0773 \\
Sig. & & 1.000 & 1.000 & 1.000 & 1.000 \\
\hline
\end{tabular}


[10] N. Özdil, F. Bozdoğan, G. Özçelik Kayseri and G. Süpüren Mengü, "Compressibility and thickness recovery characteristics of carpets," Tekstil ve Konfeksiyon, 3/2012, pp. 203-2011, 2014.

[11] Ü.H. Erdoğan, "Effect of pile fiber cross section shape on compression properties of polypropylene carpets," The Journal of The Textile Institute, vol.103, issue 12, pp. 1369-1375, 2012.

[12] M. Javidpanah, N.S. Shaikhzadeh and M. Dayiary, "Study on thickness loss of cut-pile carpet produced with heat process modified polyester pile yarn. Part II: dynamic loading," The Journal of the Textile Institute, vol. 106, issue 3, pp. 236-241, 2015.

[13] N. Celik and E. Koc, "Study on the thickness loss of Wilton-type carpets under dynamic loading," Fibres \& Textiles in Eastern Europe, vol.18, issue 1(78), pp. 54-59, 2010.

[14] K. Dubinskaite, L.V. Langenhove and R. Milasius, "Influence of pile height and density on the end-use properties of carpets," Fibres \& Textiles in Eastern Europe, vol.16, issue 3(68), pp. 47-50, 2008.

[15] N. Çelik, H.K. Kaynak and Z. Değirmenci, "Performance properties of Wilton type carpets with relief texture effect produced using shrinkable, high bulk and relaxed acrylic pile yarns," Association of Textile, Apparel and Material Professionals, pp. 43-47, September 2009.

[16] Van De Wiele carpets weave structure catalogue.

[17] D. Vuruşkan, "Carpet fiber mobility due to traffic wear," Industria Textila (Accepted for publishing).

[18] ISO 139:2005-Textiles. Standard atmospheres for conditioning and testing.

[19] http://www.wira.com/media/other/37656/WiraDynamicLoading.pdf (Available on 18.02.2017).

[20] BS ISO 2094:1999 Textile floor coverings. Determination of thickness loss under dynamic loading.

[21] ISO 1765:1986 Machine-made textile floor coverings. Determination of thickness. 